\title{
Physiological Changes during Flower Petal Developmental Stages of Jasminum sambac cv. Ramanathapuram Gundumalli
}

\author{
Shakila Sadasivam $^{1 *}$, M. Jawaharlal ${ }^{2}$, Haripriya Shanmugam ${ }^{3}$, \\ D. $\mathrm{Uma}^{4}$ and Sivakumar Uthandi ${ }^{5}$ \\ ${ }^{1}$ Department of Floriculture and Landscape Architecture, \\ ${ }^{2}$ Directorate of Extension Education, \\ ${ }^{3}$ Department of NanoScience and Technology, \\ ${ }^{4}$ Department of Biochemistry, \\ ${ }^{5}$ Department of Agricultural Microbiology, Tamil Nadu Agricultural University, \\ Coimbatore - 641 003, India \\ *Corresponding author
}

Keywords

Jasminum

sambac cv.

Ramanathapuram

Gundumalli,

physiological

changes, colour

assay, stage of

flower development

Article Info

Accepted:

25 November 2020

Available Online:

10 December 2020
An important fragrant flower crop grown in Madurai region is Jasminum sambac cv. Ramanathapuram Gundumalli. To study the postharvest quality of flower fragrance, physiological changes such as moisture content, relative water content, electrolyte leakage, flower petal thickness, changes in flower petal colour, total carbohydrate and total phenol content were studied at three flower developmental stages S1 (tight bud stage), S2 (halfopened flower stage) and S3 (fully-opened flower stage). Results on the present study revealed marked decline in moisture content, relative water content and petal thickness from S1 $(84.52 \%, 56.28 \%$ and $0.34 \mathrm{~mm})$ to S3 $(47.67 \%, 45.07 \%$ and $0.20 \mathrm{~mm})$ respectively. The chromatic parameters like lightness, hue and chroma indicated the whiteness of flower petal during $\mathrm{S} 1$ and reduction in brightness on flower opening. Electrolyte leakage, total carbohydrate and total phenol increased during S3 $(57.46 \%$, $61.71 \mathrm{mg} / \mathrm{g}$ and $1.49 \mathrm{mg} / \mathrm{g}$ ) respectively. These criteria are considered for further studies on essential oil extraction.

\section{Introduction}

Jasminum sambac cv. Ramanathapuram Gundumalli is one of the important fragrant loose flower crops grown in Madurai, Coimbatore, Dindigul and Virudhunagar districts of Tamil Nadu. This J.sambac was given Geographical Indication tag by the 
Department for promotion of Industry and Trade, Government of India in the year 2013 for its important attribute thick petals and long corolla tube.

Jasmine is a nocturnal flowering plant, anthesis occurs at 7.00 p.m to 8.00 p.m. Once the flower is harvested, its respiration rate increases and utilizes the reserved carbohydrates (Coorts, 1975). The important criterias to assess the postharvest quality of flower fragrance are size and shape (Kofranek, 1976); (Halevy and Mayak, 1973), changes in fresh flower weight (Marousky, 1973); (Borochov et al., 1976)and changes in flower petal colour (Biran and Halevy, 1974); (Mayak and Halevy, 1971). A series of events occur during flower opening which includes physiological changes such as changes in flower petal water content, thickness, colour, carbohydrate content and total phenolic content. Physiological changes play a vital role in selection of stage of flower for extraction industry. The present study on the physiological changes pertaining to this J.sambac specific to Madurai region has not yet been elucidated. Hence the present study was taken with the objective of emphasizing the physiological changes occurring during different flower developmental stages of Jasminum sambac.

\section{Materials and Methods}

\section{Collection of planting material}

Three year old, healthy jasmine plants were chosen from the field at Nilakottai district of Tamil Nadu. Flowers at three different stages of flower development viz., S1 (tight bud stage), S2 (half-opened flower stage) and S3 (fully-opened flower stage) were harvested early in the morning before 8.00 am (Figure $1)$. The harvested flowers were then placed in cakes bokes lined with aluminium foil, packed in thermocol box containing ice gel $\left(4^{\circ} \mathrm{C}\right)$, transported to the Laboratory at Horticulture College and Research Institute, Tamil Nadu Agricultural University, Coimbatore and analyses was carried out after $5 \mathrm{~h}$ of flower harvest.

\section{Moisture content}

Flowers of $20 \mathrm{~g}$ from each stage of flower development were collected and moisture content was analyzed and expressed as per cent as suggested by (Barrs and Weatherley, 1962).

$$
\begin{aligned}
& \text { Moisture content }(\%) \\
& =\frac{\text { Initial weight }(g)-\text { Final weight }(g)}{\text { Final weight }(g)} \times 100
\end{aligned}
$$

\section{Relative water content}

The per cent of water held by the flowers relative to fully turgid tissue is the relative water content of the flower petals at different stage of harvest. RWC was calculated as per the methods suggested by (Weatherly, 1950).

$$
\begin{aligned}
& \text { Relative water content }(\%) \\
& =\frac{\text { Initial weight }- \text { Turgid weight }}{\text { Turgid weight }- \text { Dry weight }} \times 100
\end{aligned}
$$

\section{Electrolyte leakage}

The total leakages of inorganic ions from flower petals were measured in terms of electrical conductivity (EC) of the bathing medium before and after treatment using Conductivity Bridge. The flower petals were punched (20 nos.) and $10 \mathrm{ml}$ of distilled water was added to it. Initial EC (Eca) was measured and the beakers containing sample were subjected to $50^{\circ} \mathrm{C}$ temperature for $30 \mathrm{~min}$. and EC was recorded as Ecb. After which, the beakers were boiled at $100^{\circ} \mathrm{C}$ for 10 mins and EC was recorded again as Ecc as per the methods suggested by (Sullivan, 1972) and calculated using the formula, 
Electrolyte leakage (\%)

$=\frac{E c b-E c a}{E c c} \times 100$

\section{Flower petal thickness}

Flowers from each stage of flowers were collected and the thickness of the petals was analyzed using a digital micrometer (Mitutoyo, Japan) and expressed as $\mathrm{mm}$.

\section{Colour assay}

The flower petal colour was measured at different flower developmental stages. The colour coordinates $\left(\mathrm{L}^{*}, \mathrm{a}^{*}, \mathrm{~b}^{*}\right)$ were measured with colorimeter (Konica-Minolta, Japan). The hue and chroma values were calculated from $\mathrm{a}^{*}$ and $\mathrm{b}^{*}$ values as suggested by Fundo et al., (2019) and calculated using the formula,

Hue $=\tan ^{-1} \frac{b *}{a *}$

Chroma $=(a *+b *)^{1 / 2}$

\section{Total phenol}

Estimation of total phenols was carried out using Folin-Ciocalteau method at all the three flower developmental stages Malik and Singh (1980). The result was expressed as mg equivalent for pyrocatechol per gram.

\section{Total carbohydrates}

Estimation of total carbohydrate was carried out using anthrone method at different flower developmental stages as suggested by Hedge and Hofreiter (1962). The result was expressed as $\mathrm{mg}$ of carbohydrate per $100 \mathrm{mg}$ of sample.

\section{Statistical analysis}

Calculation of mean \pm SE for all the physiological parameters were carried out using IBM SPSS Statistics v21.0 (IBM Company, USA) from seven biological replicates.

\section{Results and Discussion}

Significant differences in the physiological parameters were recorded at different flower developmental stages of jasmine flower. Water plays a significant role in cell expansion and flower opening. A positive turgor and osmotic potential can be maintained only when optimum water content is present in the flowers (Yamada et al., 2007). Water uptake, transport, water loss and the ability of the flower tissue to retain water are the main physiological components of water balance. As the flower opening progresses rate of respiration in flowers rapidly increases and starts declining on maturity leading to senescence. In the present experiment, there is a significant difference in the RWC and moisture content of the flowers at different developmental stage. RWC of the flower petal at tight bud stage (S1) was $56.28 \%$ which decreases gradually at half opened flower stage (S2) $(49.90 \%)$ to fully opened flower stage (S3) (45.07\%) (Figure 2).It is well known that rate of respiration increases rapidly with progression of flower opening and declines further upon attaining flower development leading to senescence. Increase in water loss during anthesis is due to increased transpiration rate (Coorts, 1975). This transpiration loss will increase further upon the harvest of the flowers. As a result, petals become delicate and their thickness reduces. In the study, petal thickness significantly decreased from $0.34 \mathrm{~mm}$ in $\mathrm{S} 1$ to $0.20 \mathrm{~mm}$ in S3 (Figure 3). Structural changes like the loosening of cell walls with time might be the reason for the upswing in flower petal water loss. As the age of flower progresses, the membrane integrity of the cell decreases and solute ion leakage increases. S3 recorded the highest electrolyte leakage $(57.64 \%)$ which is vice versa in the petals 
from S1 (32.76\%) (Figure. 2). Loss of membrane integrity due to solute ion leakage increases the permeability of plasma membrane leading to petal senescence. Membrane deterioration due to solute ion leakage is evident during flower wilting in cut carnation flowers (Eze et al., 1986). In daylily flowers, fresh weight of the flower buds were high and starts declining as the flower opening progresses which indicates decrease in flower bud weight towards senescence (Lukaszewski and Reíd, 1988).

The colour of flower petals at different stages of flower development is presented in table 1 . The luminance coordinates indicates lightness from 0 (black) to 100 (white), chromacity a* represents positive values as red, negative value as green whereas $b^{*}$ represents positive values as yellow and negative values as blue.
The lightness, hue and chroma during S1 are recorded as 96.78, 72.99 and 5.07 respectively which is chosen as standard and this indicates the bright white coloured petals. Lightness, hue during S2 and S3 were recorded as 94.11, 72.49 and 89.98, 70.73 respectively indicating reduced brightness of flower petals. The chroma values were low during all the three stages namely, S1 (5.07), S2 (4.91) and S3 (4.39) indicating colour change of flower petals. From the present study, it is observed that flower petal colour drastically reduces as flower opening progresses.

In the present study, significant differences in the total carbohydrate and total phenol content were observed. Accumulation and storage of carbohydrates and utilization of sucrose helps in flower opening (van Doorn and Van Meeteren, 2003).

Table.1 Chromatic parameters for J.sambac cv. Ramanathapuram Gundumalli flowers.

Data are represented as mean $\pm \mathrm{SE}$.

\begin{tabular}{|c|c|c|c|}
\hline Stage of flower & $\mathbf{L}^{*}$ & Hue & Chroma \\
\hline S1 & $96.78 \pm 0.7$ & $72.99 \pm 1.08$ & $5.07 \pm 0.13$ \\
\hline S2 & $94.11 \pm 0.65$ & $72.49 \pm 0.5$ & $4.91 \pm 0.06$ \\
\hline S3 & $89.98 \pm 0.91$ & $70.73 \pm 1.4$ & $4.39 \pm 0.14$ \\
\hline
\end{tabular}

Fig.1 Stages of flower development (a) S1 (tight bud stage), (b) S2 (half-opened flower stage) and (c) S3 (fully-opened flower stage.

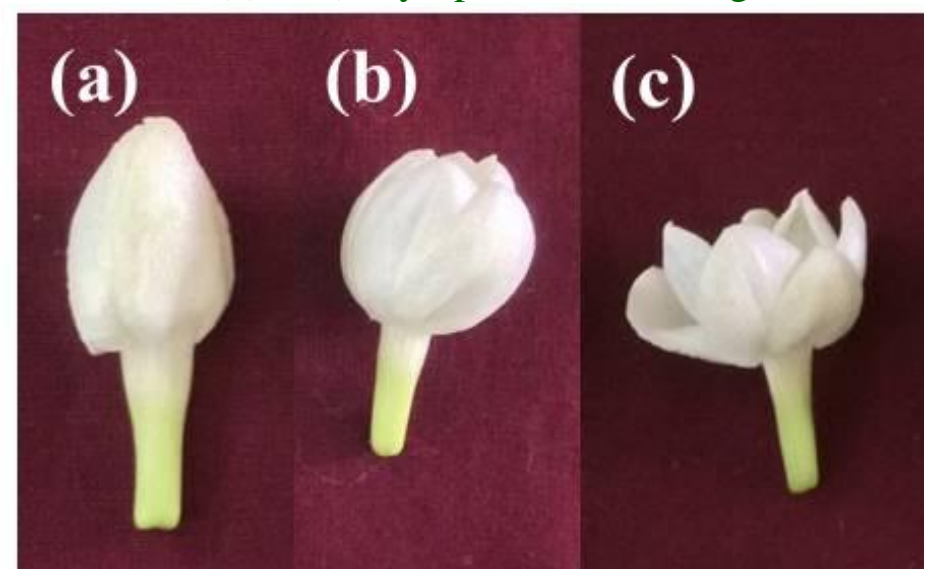


Table.2 Total carbohydrate $(\mathrm{mg} / \mathrm{g})$ and total phenol content $(\mathrm{mg} / \mathrm{g})$ at different flower developmental stages. Data are represented as mean $\pm \mathrm{SE}$.

\begin{tabular}{|c|c|c|}
\hline Stages of flower & $\begin{array}{c}\text { Total carbohydrate } \\
\text { (mg/g) }\end{array}$ & $\begin{array}{c}\text { Total phenol } \\
\text { (mg/g) }\end{array}$ \\
\hline S1 & $48.29 \pm 0.28$ & $0.27 \pm 0.01$ \\
\hline S2 & $53 \pm 0.18$ & $1 \pm 0.06$ \\
\hline S3 & $61.71 \pm 0.18$ & $1.49 \pm 0.09$ \\
\hline
\end{tabular}

Fig.2 Physiological changes occurring during the flower developmental stages

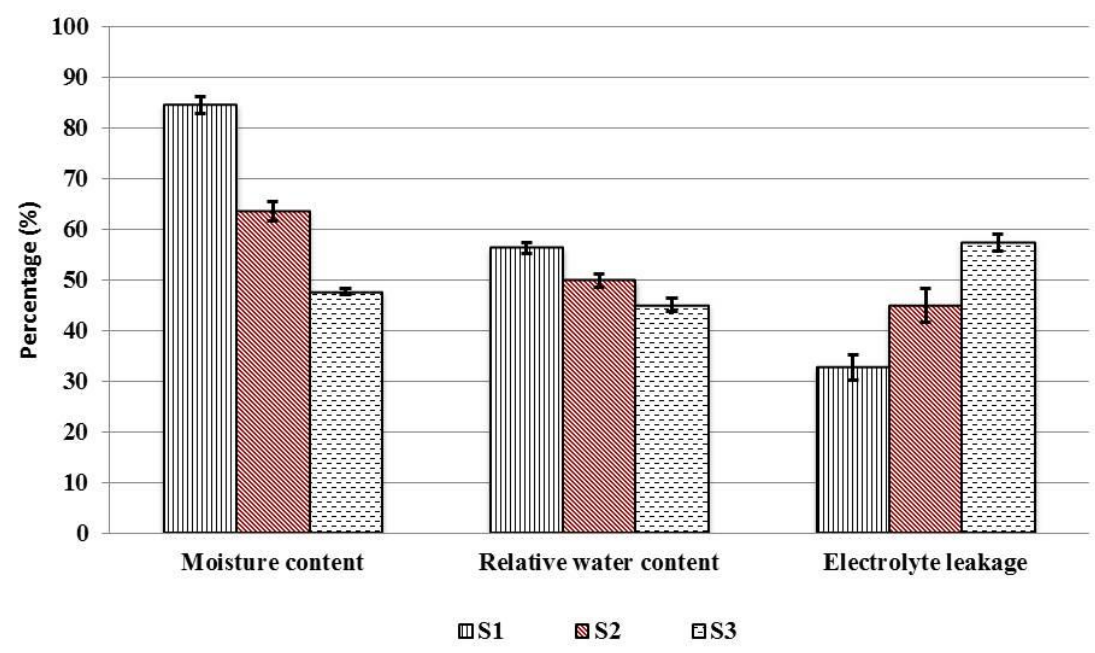

Fig.3 Flower petal thicknesses at different flower petal developmental stages

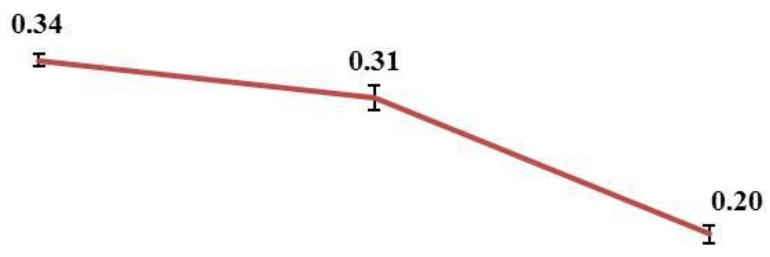

S1

S2

S3

_Flower petal thickness (mm)

Total carbohydrate content in jasmine flowers during S1 was recorded as $4.83 \mathrm{~g}$ per $100 \mathrm{mg}$ of sample which increased at the further two stages of flower development which were 5.30 and 6.17 during S2 and S3 respectively. This indicates that the total carbohydrate increases 
as the flower opening progresses. This may be due to the combination of sugar uptake and degradation of which into various polysaccharides. It is also evident from research on gladiolus where sugar content was 7-8 times higher than the starch content indicating the uptake of sugar (Yamane et al., 1993). The total phenol content at S1is0.27 mg per gram of sample which gradually increased during flower opening and at S3 it is as higher as $1.49 \mathrm{mg}$ per gram of sample. As flower opening progresses, phenol content in the flower petals increases and declines as senescence progresses. As the flower is harvested from the plant, it undergoes stress and to overcome this stress phenols are produced and help in scavenging free radicals and maintain homeotic cell balance Cavaiuolo et al., (2013); Ahmad and Tahir (2016).

The present study revealed that, the physiological changes such as moisture content, relative water content and petal thickness decreases and marked increase in electrolyte leakage, total phenol and total carbohydrate during flower opening. These physiological changes directly or indirectly correlated to the essential oil yield. Hence, these results can be used to assess the stage of flower for extraction of essential oil.

\section{References}

Ahmad, Syed Sabhi, and Inayatullah Tahir. 2016. "Increased oxidative stress, lipid peroxidation and protein degradation trigger senescence in Iris versicolor L. flowers." Physiology and Molecular Biology of Plants22 (4):507-514.

Barrs, HD, and PE Weatherley. 1962. "A reexamination of the relative turgidity technique for estimating water deficits in leaves." Australian journal of biological sciences 15 (3):413-428.

Biran, I, and AH Halevy. 1974. "Effects of varying light intensities and temperature treatments applied to whole plants, or locally to leaves or flower buds, on growth and pigmentation of 'Baccara'roses." Physiologia plantarum31 (3):175-179.

Borochov, Amihud, Shimon Mayak, and Abraham H Halevy. 1976. "Combined effects of abscisic acid and sucrose on growth and senescence of rose flowers." Physiologia plantarum36 (3):221-224.

Cavaiuolo, Marina, Giacomo Cocetta, and Antonio Ferrante. 2013. "The antioxidants changes in ornamental flowers during development and senescence." Antioxidants2 (3):132155.

Coorts, Gerald D. 1975. "Internal metabolic changes in cut flowers." 69. Reunion Anual de la Sociedad Americana de Ciencias Horticolas. St. Paul, Minn.(USA). 29 Aug 1972.

Eze, JMO, S Mayak, JE Thompson, and EB Dumbroff. 1986. "Senescence in cut carnation flowers: temporal and physiological relationships among water status, ethylene, abscisic acid and membrane permeability." Physiologia plantarum68 (2):323-328.

Fundo, Joana F, Fátima A Miller, Gabriela F Mandro, Andréia Tremarin, Teresa RS Brandão, and Cristina LM Silva. 2019. "UV-C light processing of Cantaloupe melon juice: Evaluation of the impact on microbiological, and some quality characteristics, during refrigerated storage." LWT 103:247-252.

Halevy, AH, and S Mayak. 1973. "Transport and conditioning of cut flowers." Symposium on Cultivation of Flowers under Protection in the Mediterranean Regions 43.

Hedge, JE, and BT Hofreiter. 1962. "Estimation of carbohydrate." Methods in carbohydrate chemistry. Academic Press, New York:17-22. 
Kofranek, Anton M. 1976. "Opening flower buds after storage." Symposium on Production of Potted Plants and Cut Flowers 64.

Lukaszewski, Tim A, and Michael S Reíd. 1988. "Bulb-type flower senescence." IV International Symposium on Postharvest Physiology of Ornamental Plants 261.

Malik, Chander Parkash, and MB Singh. 1980. "Plant enzymology and histoenzymology."

Marousky, F J. 1973. "Recent advances in opening cut bud chrysanthemum flowers." Hort. Sci.8 (3):199-202.

Mayak, S, and AH Halevy. 1971. "Water stress as the cause for failure of flower bud opening in iris." Amer Soc Hort Sci J.

Sullivan, Charles Y. 1972. "Mechanisms of heat and drought resistance in grain sorghum and methods of measurement." Sorghum in Seventies. Oxford \& IBH Pub. Co. van Doorn, Wouter G, and Uulke Van Meeteren. 2003. "Flower opening and closure: a review." Journal of experimental botany54 (389):18011812.

Weatherly, PE. 1950. "Studies on the water relations of the cotton plants." The field.

Yamada, Kunio, Masakazu Ito, Tomoko Oyama, Maiko Nakada, Masahiro Maesaka, and Shohei Yamaki. 2007. "Analysis of sucrose metabolism during petal growth of cut roses." Postharvest Biology and Technology43 (1):174-177.

Yamane, Kenji, Satoko Abiru, Nobuaki Fujishige, Ryozo Sakiyama, and Ryosuke Ogata. 1993. "Export of soluble sugars and increase in membrane permeability of gladiolus florets during senescence." Journal of the Japanese Society for Horticultural Science62 (3):575-580.

\section{How to cite this article:}

Shakila Sadasivam, M. Jawaharlal, Haripriya Shanmugam, D. Uma and Sivakumar Uthandi. 2020. Physiological Changes during Flower Petal Developmental Stages of Jasminum sambac cv. Ramanathapuram Gundumalli. Int.J.Curr.Microbiol.App.Sci. 9(12): 3445-3451. doi: https://doi.org/10.20546/ijcmas.2020.912.410 